\title{
A EDUCAÇÃO AMBIENTAL COMO VEÍCULO DE INCLUSÃO SOCIAL NA ESCOLA RURAL 21 DE ABRIL - LINHA RINCÃO FUNDO - PANAMBI/RS
}

\author{
Glauciéli Quevedo Pinheiro Hack, Liane de Souza Weber
}

\section{RESUMO}

O trabalho realizado teve como objetivo geral Acompanhar a prática em Educação Ambiental na Escola Municipal 21 de Abril. A escola está localizada na zona rural de Panambi - RS, mais precisamente na Linha Rincão Fundo, distante $10 \mathrm{~km}$ do centro do município. Neste sentido se investigaram valores e atitudes ambientais nos alunos participantes do Projeto Criar, analisando os principais aspectos que formam a base ambiental dos adolescentes participantes e identificando que tipos de materiais podem ser usados, e ou reutilizados na fabricação de novos objetos nos processos de educação. Como método de coleta de dados utilizou-se questionários. A pesquisa identificou o conhecimento dos alunos participantes do Projeto Criar. Os resultados obtidos demonstram os vários fatores ambientais atuais que preocupam a humanidade, porquê os fenômenos naturais desequilibram a harmonia entre o homem e o meio ambiente, gerando prejuízos em todos os ecossistemas, na saúde dos seres humanos e na economia mundial. Pois o ser humano está mais preocupado com o seu conforto, com o seu modo de vida. Os problemas ambientais ficam relegados a um segundo plano ou nem são reconhecidos. Por isso o Projeto Criar chama a atenção da sociedade para uma juventude que possa contribuir para um meio ambiente sustentável e para que ações como estas possam trazer benefícios sociais.

Palavras-chave: Meio Ambiente; Educação Ambiental; Rural; Projeto Criar.

\section{ABSTRACT}

This research had as general goal to accompany the practice in Environment Education at the Municipal School 21 de Abril. The school is located in a rural zone of Panambi-RS, more precisely in Linha Rincão Fundo, $10 \mathrm{~km}$ away from the center of the Municipality. In this sense, environment values and attitudes of the students taking part in the Projeto Criar will be investigated, analyzing the main aspects that form the environment basis of the participant teenagers and identifying what kind of materials can be used and or reused in the making of new objects in the process of education. Questionnaires were used as a data collecting method. The research identified the knowledge of the students taking part in the Projeto Criar. The results obtained along this work show the various current environment factors that are of concern to mankind, mainly because the natural phenomena are creating a harmony imbalance between man and environment, generating losses in all ecosystems, to the health of human beings and to the world economy. Because the human being is more concerned about his comfort and way of life. The environment problems are left aside or not even recognized. Therefore Projeto Criar calls the attention of society to a youth that may contribute to a sustainable environment and that actions like these may bring great social benefits.

Key words: Environment; Environment Education; Rural; Projeto Criar. 


\section{INTRODUÇÃO}

O Planeta vive um período de grandes avanços tecnológicos e científicos e, por outro lado, uma grande degradação dos ecossistemas e de todo o ambiente que o rodeia. A própria humanidade tem acompanhado essa degradação ambiental, manifestando distúrbios físicos, psicológicos e sociais, tanto individuais como coletivos.

A natureza está dando um grande número de avisos, como o aumento do CO 2 atmosférico, o aumento gradativo da temperatura planetária a grande perda da biodiversidade, a aceleração do derretimento das geleiras e das calotas polares, a redução da camada de ozônio demonstrando a gravidade da situação atual e que exige ações urgentes e profundas para alterar o atual rumo, que está levando à destruição das condições de vida e da própria espécie humana.

A simples existência da variedade destes seres (biodiversidade) é fundamental para a garantia da estabilidade ambiental, a capacidade funcional dos ecossistemas em executar os serviços oferecidos ao equilíbrio da natureza, dos quais somos dependentes, como a reciclagem dos resíduos, seu papel no ciclo hidrológico, a autodepuração dos rios...

Estes dados demonstram que a forma que o ser humano está se apropriando dos recursos ultrapassou o limiar da sustentabilidade. Estamos vivendo a extinção massiva, mas pela primeira vez o responsável por este fenômeno, o próprio homem, têm consciência das consequencias de suas atitudes.

Há uma preocupação com os problemas ecológicos atuais, onde o ambiente e a proteção dos Recursos Naturais renováveis e a defesa do ambiente saudável, estão sob uma multiplicidade de enfoques. Nesse sentido, não é mais uma questão que diz respeito apenas aos cientistas, aos biólogos, aos químicos, aos naturalistas etc. Passa a ser uma preocupação de todos.

O meio rural é associado ao natural, ou seja, considerado o espaço no qual o homem está em contato direto com a natureza. Durante um longo período o campo foi considerado como lugar da rusticidade, do inculto, do atraso, entre tantos outros atributos negativos.

Nos últimos anos, mais especificamente a partir da década de 1990, a escola rural, que ao longo da história serviu basicamente como instrumento para o preparo mínimo de mão-de- obra, finalmente abre-se para a construção de um novo modelo pedagógico que leva em conta as características e necessidades próprias do aluno do campo no seu espaço cultural.

A escola rural vem buscando a valorização do campo, que engloba os espaços da floresta, da pecuária, da agricultura, como espaço de inclusão social, a partir de uma nova visão de desenvolvimento.

A nova escola rural passa a considerar a necessidade de promover atividades curriculares e pedagógicas direcionadas a promoção de um desenvolvimento sustentável e solidário no campo.

\section{Problema}

A consciência de que um dos grandes problemas ambientais do mundo moderno é o lixo e a degradação do meio ambiente, gerada pela má destinação de resíduos, faz-se necessário o papel fundamental da escola, que influencia na formação do cidadão crítico e reflexivo. Para tanto, algumas escolas trabalham isso em forma de projetos.Esta pesquisa por sua vez visou 
conhecer o trabalho de educação ambiental no Projeto Criar na Escola Municipal de Ensino Fundamental 21 de Abril, que acontece e no turno da tarde com alunos de 5 a a 8a série com idade entre 10 a 16 anos, pré selecionados e que estão em situação de risco, estes permanecem em tempo integral na escola, duas vezes por semana.

\section{Objetivos}

\section{Objetivo Geral}

O objetivo geral da pesquisa consistiu em reconhecer e acompanhar as práticas em Educação Ambiental do Projeto Criar, na Escola Municipal de Ensino Fundamental 21 de Abril situado na zona rural/na Linha Rincão Fundo/Panambi-RS, com a finalidade de sugerir ações práticas relacionadas a sustentabilidade ambiental.

\section{Objetivos Específicos}

-Investigar valores e atitudes ambientais nos educandos participantes do Projeto Criar.

-Conhecer a opinião dos alunos sobre as questões ambientais, já que essas formam a base ambiental dos adolescentes participantes do Projeto.

-Desenvolver ações ambientais, tais com: conhecer que tipo de papeis se pode coletar, para serem reutilizados na fabricação de novos objetos (cartões, ponteira de lápis, etc.) mostrando uma forma de sustentabilidade ambiental.

\section{Justificativa}

Este trabalho consistiu em reconhecer e acompanhar as práticas em Educação Ambiental do Projeto Criar. Partindo-se da necessidade que a escola tem,de formar cidadãos conscientes, capazes de decidir e atuar na realidade socioambiental de modo comprometido com a vida, com o bem-estar de cada um e da sociedade.

A perspectiva ambiental consiste num modo de ver o mundo em que se evidenciam as interrelações e a interdependência de diversos elementos na constituição e manutenção da vida. Passou-se para o âmbito da escola e para os setores que organizam e estruturam a dinâmica educacional do país esta responsabilidade.

A escola é capaz de propiciar uma continua reflexão e a apropriação de valores que remetem a um ambiente equilibrado em harmonia com o meio, com os outros seres vivos, um ambiente onde todos poderão viver com qualidade usufruindo dos recursos ambientais sem compromete as gerações futuras. Para tanto a escola 21 de Abril, localizada na Zona Rural vem desenvolvendo um projeto contribuindo para a conscientização de práticas sustentáveis. 


\section{Revisão Bibliográfica}

\section{A importância da educação ambiental}

A Educação Ambiental é um processo de reconhecimento de valores e clarificações de conceitos, objetivando o desenvolvimento da conscientização ambiental e modificando as atitudes em relação ao meio, para entender e apreciar as inter-relações entre os seres humanos, suas culturas e seus meios biofísicos. A educação ambiental também está relacionada com a prática das tomadas de decisões e a ética que conduzem para a melhoria da qualidade de vida, dessa forma a educação ambiental tenta despertar em todos a consciência de que o ser humano é parte do meio ambiente. Ela tenta superar a visão antropocêntrica, que fez com que o homem se sentisse sempre o centro de tudo esquecendo a importância da natureza, da qual é parte integrante.

Sendo a escola uma mediadora na aquisição de conhecimentos, cabe a ela o papel de mobilizar os alunos e os pais a fim de conscientizar a respeito dos problemas ambientais, fornecendoIhes as informações sobre os fenômenos que estão contribuindo para o desequilíbrio ecológico, tais como o aumento de doenças, alterações no clima, prejuízo na agricultura, contaminação da água, do ar, entre tantos outros fatores inerentes à ação humana.

A Educação Ambiental é uma peça chave no processo de formação da consciência sobre a necessidade de preservar os recursos naturais. Nessa tarefa educativa, a escola cumpre um papel fundamental como promotora e mobilizadora de pais, professores, alunos, organizações e instituições a fim de melhorar o ambiente em que vivemos.

É importante que a escola seja, em parte, um oásis e que ela continue a funcionar nas circunstâncias mais movimentadas, mesmo em caso de guerra ou de grande crise econômica. Ela permanece, senão um "santuário", pelo menos um lugar cujo estatuto "protegido" é reconhecido. Quando a violência urbana ou a repressão policial chegam às escolas, os espíritos ficam chocados. E é esse choque que faz com que cada povo tenha uma concepção de educação.

As mudanças visualizadas priorizam um trabalho de conscientização envolvendo toda e a comunidade escolar, destacando a importância da reciclagem, possível de ser realizada na separação do lixo orgânico, utilizado na horta doméstica. (MOTA, 2003) reforça o sentido dos 4r's: reduzir, racionalizar, reutilizar e reciclar. Desse modo, a tendência mundial, nos últimos anos é o reaproveitamento dos produtos jogados fora, à reutilização de novos objetos, através da reciclagem (aproveitar materiais usados como matéria-prima na fabricação de novos produtos).

\section{A problemática ambiental e o homem}

A degradação do Meio Ambiente teve início com o homem primitivo, mas as transformações mais profundas e catastróficas são mais recentes, a partir da revolução industrial, produtos da incansável busca do conforto, do lucro e do uso abusivo e crescente da tecnologia.

A evolução das espécies, o aglomeramento progressivo, o desenvolvimento tecnológico e a busca constante do conforto, comprometeram consideravelmente a qualidade de vida no planeta. 
O acúmulo de resíduos, a degradação do Meio Ambiente, o uso indiscriminado dos recursos naturais, vêm promovendo a proliferação de doenças que desafiam os avanços da Ciência.

O lixo é considerado basicamente todo e qualquer material fora de lugar proveniente das atividades humanas, quer nas indústrias, estabelecimentos comerciais, fábricas, hospitais, residências, etc. Mais da metade do que é chamado de "lixo" e forma montanhas de resíduos (os populares lixões) na maioria das cidades, pode ser reciclado e reutilizado. Além dos lixões a céu aberto, existem outros fatores que comprometem largamente a qualidade de vida, entre eles, pode-se citar o desperdício da água, gerado pela descrença de que este é um bem não renovável e que está cada vez mais comprometida. Outro fator preocupante são os desmatamentos, que em muitos casos visam o lucro simplesmente, sem considerar o desequilíbrio da natureza e a extinção de espécies animais e vegetais que já existiam muito antes do ser humano entrar para o cenário da história.

A Educação Ambiental, a consciência de preservação deve partir de cada integrante da população antes de tudo, devem-se rever os valores que orientam o desenvolvimento. O ser humano deve repensar o seu modo de viver, de produzir, construir e descartar, aprender a utilizar os recursos naturais e assim alcançar um objetivo comum. Conscientizar-se a si e a seus semelhantes sobre a importância de preservar o meio em que vive, criando um modelo de desenvolvimento equilibrado, onde crescer não seja sinônimo de destruir, poluir e depredar. Isso poderá garantir a sua sobrevivência e a das futuras gerações.

Para que o homem reconquiste a melhoria na qualidade de vida é necessário ainda produzir alimentos saudáveis, gerar empregos, redistribuir a renda, rever os valores, enfim, construir uma sociedade mais humana, onde a solidariedade, a verdade, a justiça, e a qualidade de vida, sejam metas prioritárias e fundamentais.

No fator ligado á cidadania, pressupõe-se necessária a articulação de todos os segmentos necessários à implantação de programas e projetos, numa rede de solidariedade e parceria para promover a mudança necessária. Sem essas ações pouco se muda, não basta apenas cada pessoa fazer a sua parte.

A Educação Ambiental e a conscientização devem fazer parte no processo escolar, para que o cidadão construa um mundo sustentável dessa forma. A conscientização implica em sensibilização e na busca da qualidade de vida (MELLER, 2002,p.48).

\section{Educação Ambiental como instrumento de Conscientização}

A Educação ambiental é um instrumento de conscientização no processo escolar, para a conscientização do cidadão na construção de um mundo sustentável e do resgate a uma melhor qualidade de vida.

A Educação Ambiental deve ser trabalhada como interdisciplinaridade, até porque é uma disciplina que está inserida em todas as outras. Desde o currículo do Ensino Fundamental e mesmo antes da criança entrar na escola, na família, os pais devem orientar na prática, o que significa cuidar do meio ambiente.

O desequilíbrio da natureza permanecerá enquanto a ocupação humana não respeitar uso das terras e não adotar práticas adequadas de preservação. Enquanto a expansão urbana não for planejada, respeitando claros limites de infra-estrutura, como a malha viária e não forem tomados os devidos cuidados de implantação e conservação, enfim, enquanto não for implementada uma política global, integrando ações que possam ser priorizadas preventiva e 
coletivamente para permitir a renovação dos recursos naturais, o desequilíbrio da natureza permanecerá (BARROS \& PAULINO, 2002,p.84).

A evolução da tecnologia já permite a limpeza de rios poluídos, mas existem muitas maneiras de prevenir a contaminação das águas, como por exemplo: A construção de digestores que decompõe a matéria orgânica do esgoto e do lixo, onde o gás metano produzido pode ser utilizado como combustível e os resíduos sólidos como adubo, eliminando, deles os metais pesados e as substâncias tóxicas; a proibição e a fiscalização do lançamento de produtos químicos na água; o controle da poluição nos garimpos; a fiscalização da exploração do transporte e da distribuição do petróleo em acidentes com vazamentos do produto; a limpeza da água utilizando técnicas com produtos que absorvam o óleo (palha de trigo, de arroz) ou bactérias que digerem óleo; o uso correto de fertilizantes, evitando dessa forma os processos de eutrofização. Esse processo é determinado pelo enriquecimento das águas por nutrientes, favorecendo assim a proliferação de algas.

Do mesmo modo, não podemos deixar de ressaltar a importância da preservação do solo, pois este, de maneira geral é a fonte principal de sustento para a humanidade, por isso são imprescindíveis medidas para sua preservação, com uma agricultura ecológica, desenvolvida a partir de práticas agrícolas que respeitem os ecossistemas de cada região.

Entre outros tópicos, Zamberlam e Froncheti (2001,p.56), fornecem elementos para o planejamento da agricultura como alternativa na propriedade familiar e de como aproveitar a fertilidade natural do solo, o manejo de ervas, pragas, e doenças; incluindo algumas receitas para a melhoria na fertilidade do solo, receitas para a prevenção e controle de pragas, através do uso de inseticidas e fungicidas naturais.

Entretanto são necessárias outras medidas para a preservação do solo: observar e evitar cultivos que contribuam com a erosão, principalmente em terras áridas, limitar a criação de animais em áreas impróprias (áridas e semi-áridas), deve-se preservar a vegetação natural, principalmente em encostas e às margens de rios e lagos porque, além de evitar a erosão e o assoreamento dos rios, essa vegetação contribui também para a preservação das espécies selvagens e desviam a ação das pragas para as plantas não produtivas. Em alguns casos, o controle da erosão pode ser beneficiado com uma agricultura adequada ao clima e ao solo, colocando restos de folhas secas e cascas das culturas entre as plantas, diminuindo a perda da manta florestal provocada pela água das chuvas. Outra solução bastante utilizada para a preservação de encostas são as culturas em terraços, com as sementes sendo plantadas seguindo as curvas de níveis.

A reciclagem é um processo bastante antigo, já na idade média, sucateiros derretiam as espadas dos guerreiros para reaproveitar o metal. Uma das formas mais antigas de reciclagem é a compostagem, que era utilizada por antigas civilizações na produção de cereais. A compostagem é o processo de decomposição biológica da matéria orgânica contida em resíduos animais ou vegetais, tendo como resultado um material, relativamente, estável denominado de composto (BALERINI, 2000).

Se todos os outros problemas de destruição do meio ambiente têm solução, com o lixo não é diferente. Trabalhar com a reciclagem do lixo é possível, pois o lixo urbano é ainda o que mais polui e contamina a terra. Não é preciso ser cientista, nem fazer parte de grupos de ambientalistas, para ser observar e constatar esta problemática.

O processo de compostagem é o reaproveitamento dos resíduos orgânicos normalmente transformados em adubo. Sabe-se que a natureza é sábia e resolve este problema pela ação de microorganismos decompositores (BARROS \& PAULINO, 2003). 
A reciclagem do papel no Brasil atualmente está na faixa dos $30 \%$ da produção, comparandose com o resto do mundo. Após a coleta seletiva de recortes e sobras de papel usado, estes recebem o nome de aparas. Desde 1977, estão definidas 22 categorias de aparas, classificadas de acordo com a qualidade. (BARROS \& PAULINO, 2002).

Colaborar com a reciclagem é a melhor maneira de ajudar a preservar o ambiente, dessa forma estaremos economizando matéria prima e energia fornecida pela natureza, além de diminuir a extração de recursos naturais. Os benefícios obtidos da reciclagem são enormes para a sociedade, para a economia do pais e para a natureza.

\section{METODOLOGIA}

É preciso que o docente tenha clareza do que significa pesquisa, pois necessita desta para caracterizar-se como um profissional empenhado e consciente do mundo em que vive e suas peculiaridades. $\mathrm{O}$ ensino por si só já se denomina como pesquisa, mas é preciso acima de tudo que o professor-educador tenha consciência disto. Freire nos diz:

[...] não há ensino sem pesquisa em ensino. Esse que - fazeres se encontram um no corpo do outro. Enquanto ensino, continuo buscando, reprocurando. Ensino porque busco, porque indaguei, porque indago e me indago. Pesquiso para constatar, constatando intervenho, e intervindo educo e me educo. Pesquiso para conhecer o que ainda não conheço e comunicar ou anunciar a novidade (FREIRE, 1998,p.69).

Esta pesquisa se respalda nas técnicas e métodos conhecidos como pesquisa de campo exploratória e com abordagem quantitativa.

Tecendo considerações a respeito deste tipo de pesquisa, Minayo et al. (1994) afirmam que esta responde a questões muito particulares, preocupando-se com um nível de realidade que não pode ser quantificado. Assim, a pesquisa qualitativa trabalha com o universo de significados, motivações, aspirações, crenças, valores e atitudes. Dedica-se àquilo que corresponde a um espaço mais profundo das relações, dos processos e dos fenômenos que não podem ser reduzidos à operacionalização de variáveis. A variável qualitativa segundo Almeida (1989)

\footnotetext{
é uma variável que se refere a uma característica ou atributo da pessoa e não pode ser manipulada ou é de difícil de ser manipulada. As variáveis que indicam características humanas como sexo, educação, status, atitude, são variáveis qualitativas. Elas são normalmente descritivas, mas podem ser quantificadas.(ALMEIDA, 1989. p. 60)
}

Assim, a pesquisa busca associar dados qualitativos e quantitativos que, neste caso, se complementam na análise da realidade estudada. Esse procedimento metodológico pretende utilizar-se da vivência, da experiência e do cotidiano dos educandos da Escola 21 de Abril participantes do Projeto Criar, a cerca da Educação Ambiental. O que se pretende avaliar não é a quantidade de conhecimento, mas a capacidade destes em acioná-los as sua prática na vida familiar. Portanto, os instrumentos de avaliação só cumprem com sua finalidade se puderem diagnosticar o uso funcional e contextualizado dos conhecimentos ambientais. Para tanto, o processo metodológico contou a aplicação de questionário e posterior entrevista semiestruturada. 


\section{Caracterização do Local da Pesquisa}

A Escola Municipal de Ensino Fundamental 21 de Abril está localizada a $10 \mathrm{~km}$ do centro da Cidade de Panambi-Rio Grande do Sul, na Linha Rincão Fundo. O município localiza-se no Planalto Rio-grandense, região caracterizada pelos campos serranos, é conhecida como Cidade das Máquinas, ostenta o título de 3o Pólo Metal-Mecânico do estado devido ao seu diversificado parque industrial - o qual se deve à presença de ferrarias, serrarias e oficinas artesanais desde o início da colonização. A língua alemã prevalece na zona rural e entre boa parte da população urbana.

Foi uma das primeiras escolas instaladas no interior do município. Criada em 1921, sendo uma escola comunitária, durante 45 anos era mantida pela comunidade evangélica. 0 primeiro professor foi Henrich Brückemann. Em 1949 foi oficializada como Escola Sinodal 21 de Abril, sendo filiada ao Sínodo Rio-Grandense. O primeiro prédio desta escola se localizava onde está o prédio atual.

$\mathrm{Na}$ década de 60 foi construído um novo prédio escolar próximo à esquina que dá acesso ao Sr. Bühring, a denominada "Brizoleta", por ser Leonel Brizola o governador da época. Foi inaugurada em 12/11/1961 sendo o prédio de madeira. Em 1\%/03/1964 iniciou seu trabalho na escola a professora Nelcy Radmann.

Por ser de madeira, a "Brizoleta" foi demolida na década de 70, quando a administração municipal construiu um novo prédio de alvenaria no local onde está o prédio atual. Inaugurado dia 27/02/1977, oficializou-se a Escola Municipal 21 de Abril que atendia alunos de $1 \underline{a}$ à $5 \underline{a}$ séries. Havia, porém um grande desejo por parte da comunidade em ter 0 ensino de 1 o grau completo.

Em 1985 foi criada a 6a série e no ano seguinte a 7ạ, sendo necessária uma ampliação do prédio. A inauguração do prédio B da escola foi no dia 12/10/1986. Em 1987 com a implantação da 8ª série, a escola finalmente tornou-se de 1 o grau completo.

No ano de 1989 houve a construção da quadra de esportes e instituiu-se a Pré-escola. Em 1995 foi construído o telhado entre os dois prédios e em 1998 a ACPM adquiriu a máquina de xerox. Atualmente a escola conta com os mesmos prédios e instalações acrescido de um laboratório de informática, mantendo o ensino fundamental de 8 anos e educação infantil ao 4 을 ano dentro na nova lei de ensino fundamental de 9 anos.

\section{O Projeto Criar}

O projeto Criar foi criado em novembro de 2007 com o objetivo de oportunizar crianças e adolescentes adquirirem conhecimentos básicos sobre o meio ambiente sustentável e desenvolverem ações capazes de promover a transformação social e ambiental em sua comunidade, ocupando seu tempo ocioso com atividades pedagógicas e educativas em um ambiente favorável a esta construção.

Os alunos participantes do projeto têm aula normal no turno da manhã, e no turno da tarde é desenvolvido o mesmo, duas vezes por semana, terças-feiras e quintas-feiras. São oferecidas 20 vagas prioritariamente para os alunos considerados em situação de risco. 0 comprometimento da família é fundamental, pois os alunos que não tiverem assiduidade perdem a vaga, sendo substituído por outro. Os alunos têm refeições, iniciando pelo almoço ao 
meio-dia e lanche no meio da tarde. As aulas acontecem através de oficinas temáticas, nas quais os profissionais se utilizam da teoria e prática e instrumentos didático-pedagógicos, como apostilas, materiais áudios-visuais, recursos tecnológicos, materiais diversos e experimentos.

O projeto conta com parceria da Prefeitura Municipal, Secretaria Municipal de Educação e Cultura e Secretaria Municipal da Indústria e Comércio, Associação de Recuperação e Preservação Ambiental do Município - Arpa Fiúza, Conselho Municipal do Meio Ambiente, Cooperativa Agropecuária - Cotripal, Sindicato Rural entre outras.

\section{Questionário}

O questionário composto por 5 questões fechadas (apêndice A), foi aplicado aos alunos participantes do projeto Criar da Escola 21 de Abril, sendo que, foram entrevistados 16 alunos, 8 do sexo feminino e 8 do sexo masculino com idades entre 11 anos e 16 anos no intuito de absorver os seus conhecimentos.

Segundo Parasuraman (1986), o questionário é muito importante na pesquisa científica, especialmente nas ciências sociais. Para Gressler (2004), a maior vantagem do questionário é a sua versatilidade, além disso, assegura maior liberdade para expressar opiniões.

As entrevistas serviram de complemento às informações obtidas através dos questionários. Conforme Triviños (1987) a entrevista semi-estruturada é um dos principais meios que o investigador dispõe. Segundo ele, essa técnica parte de certos questionamentos básicos, apoiados em teorias e hipóteses, que interessam à pesquisa, e que, em seguida, oferecem amplo campo de interrogativas, fruto de novas hipóteses que vão surgindo à medida que se recebem as respostas dos informantes. Desta maneira, o informante, seguindo espontaneamente a linha de seu pensamento e de suas experiências dentro do foco principal colocado pelo investigador, começa a participar na elaboração do conteúdo da pesquisa. (TRIVIÑOS, 1987).

A entrevista abordou temas referentes ao local, à educação ambiental, o projeto. O conteúdo dessas entrevistas procurou descrever o modo de pensar e agir dos entrevistados relacionando tais variáveis a determinantes culturais, além de buscar delinear o ambiente sócio-ambiental no qual estão inseridos. Assim, os sujeitos entrevistados foram selecionados de forma intencional por configurarem-se em informantes qualificados. As entrevistas foram realizadas no mês de agosto de 2009 sendo entrevistados a Diretora da Escola 21 de Abril e um representante do corpo docente do projeto e 16 educando participantes do projeto. Posteriormente efetivou-se a reconstrução dos diálogos somados a análise dos questionários, na tentativa de descrever os sujeitos pesquisados em relação aos seus modos de pensar e agir, e principalmente sua postura e compreensão a cerca da temática ambiental. Além disso, tais informações buscam revelar o grau de conscientização dos sujeitos investigados no que se refere a suas práticas cotidianas.

\section{Métodos}

A partir dos resultados obtidos, foi organizada uma oficina de reciclagem de papel. Essa constituiu nos seguintes passos os alunos durante uma semana coletaram papeis nas salas de aula (folhas de A4, folhas de caderno usadas ao invés de irem para o lixo iam para uma caixa em 
separado), durante a oficina os alunos participantes do projeto puderam fazer cartões, embalar caixas de sapatos, e conhecer as várias possibilidades que o papel reciclado proporciona.

O questionário foi aplicado as alunos do Projeto Criar, que freqüentam no turno da tarde aulas de educação ambiental. O questionário foi aplicado a 16 alunos, sendo 8 do sexo masculino e 8 do sexo feminino.

\section{RESULTADOS E DISCUSSÃO}

Foi aplicado aos alunos um questionário sobre questões relacionadas ao meio ambiente conforme dados apresentados e sistematizados nos gráficos a seguir.

$\mathrm{Na}$ primeira questão, os alunos responderam "o que é meio ambiente?", cujos resultados estão apresentados no Figura 4.1. Verificou-se que $6 \%$ (1) respondeu que meio ambiente é a base para a qualidade de vida dos seres humanos, $25 \%$ (4) responderam que é o meio onde vivemos, 69\% (11) responderam todas as respostas estão corretas, ao analisar essa alternativa pode-se observar que a escola (projeto) desenvolvem ações que estimulam a aprendizagem dos alunos quanto a preservação do meio ambiente. Nessa questão trabalhou-se com questões direcionadas para que os alunos pudessem optar conforme sua opinião.

\section{1 - O que é Meio Ambiente?}



$69 \%$

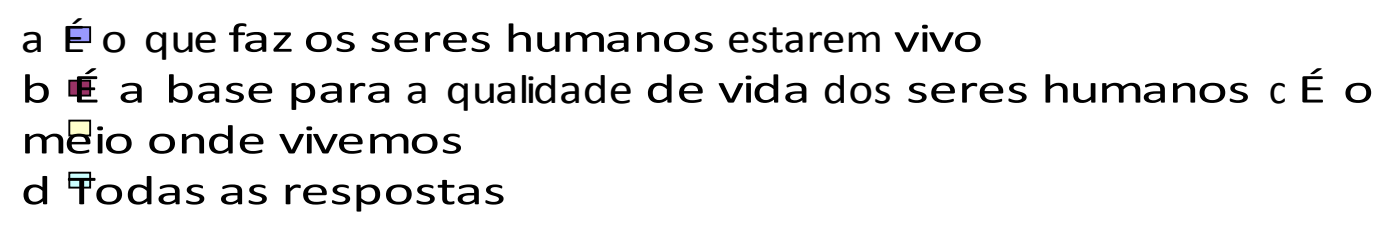

FIGURA 4.1 Questão 1

$\mathrm{Na}$ segunda questão, perguntou-se a respeito de qual matéria você tem aula sobre meio ambiente? Dos 16 alunos que responderam ao questionário obtiveram-se as seguintes 
respostas. 89\% (14) afirmaram ser a matéria de Ciências e 11\% (2) alunos responderão ser duas matérias, ou seja, em Ciências e Geografia. As respostas dessas questões indicam que a escola desenvolve ações pedagógicas que estimulam os alunos a terem ações de preservação com o meio ambiente.

2- Em qual matéria você tem aula sobre meio ambiente?

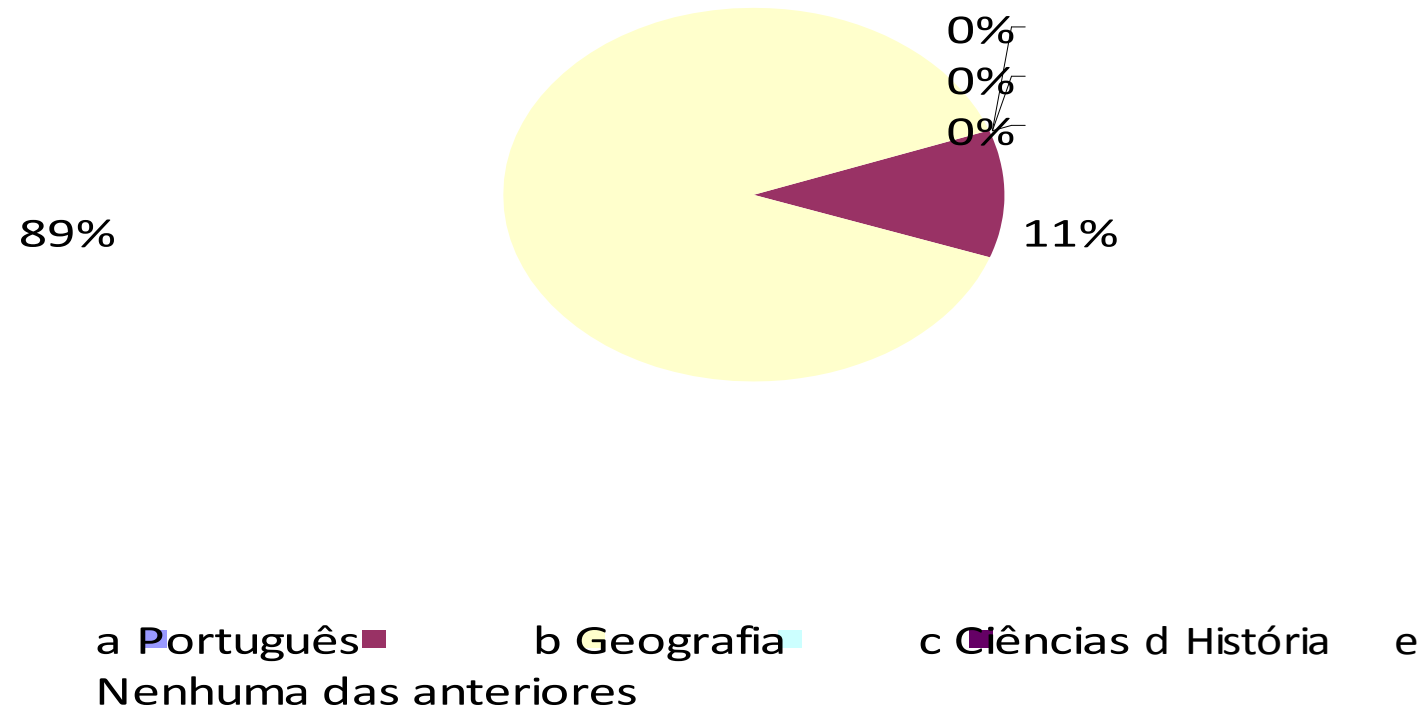

FIGURA 4.2 Questão 2

Na terceira questão procurou-se saber sobre o que a escola ensina sobre Meio Ambiente? Conforme a figura 4.3, verificou-se que $19 \%$ (3) responderam que o meio ambiente é o que nos faz estar vivo, que podemos destruir todo o meio ambiente que ele não é necessário para a nossa sobrevivência, não houve respostas. 19\%(3) responderam que é necessário preservar o meio ambiente para que no futuro todos possam utilizar as coisas existentes nele. E 62\% (10) responderam todas as respostas 
HACK \& WEBER, vol.(4), n4, p. 801-815, 2011.

Monografias Ambientais (e-ISSN: 2236-1308)

REMOA

3 - O que a escola ensina sobre Meio Ambiente?

$19 \%$



$62 \%$

a Que o Meio Ambiente é o que nos faz estar vivo

b Que podemos destruir todo o Meio Ambiente porque ele não necessário para a nossa sobrevivência

c Que é necessário preservar o Meio Ambiente para que no futuro todos possam utilizar as coisas existentes nele

d Todas as respostas

FIGURA 4.3 Questão 3.

Na quarta questão, "Problemas ambientais mais críticos no seu município" os alunos poderiam optar por mais de uma alternativa, sendo delimitado a estes no máximo três. As respostas obtidas foram as seguintes: 16 afirmaram ser a poluição da água, 11 desmatamento, 9 poluição do ar, 9 esgoto não tratado, 2 uso abusivo dos agrotóxicos, 1perda da biodiversidade,1lixo não acondicionado, 1 poluição sonora. Não foram optadas alternativas poluição visual, outro. $100 \%$ dos alunos estão muito preocupados com a poluição das águas enquanto $68 \%$ estão com o desmatamento existente no município. 
HACK \& WEBER, vol.(4), n4, p. 801-815, 2011.

Monografias Ambientais (e-ISSN: 2236-1308)

REMOA

4 - Assinale nos itens relacionados a seguir três (3) problemas ambientais mais críticos no seu município:

1

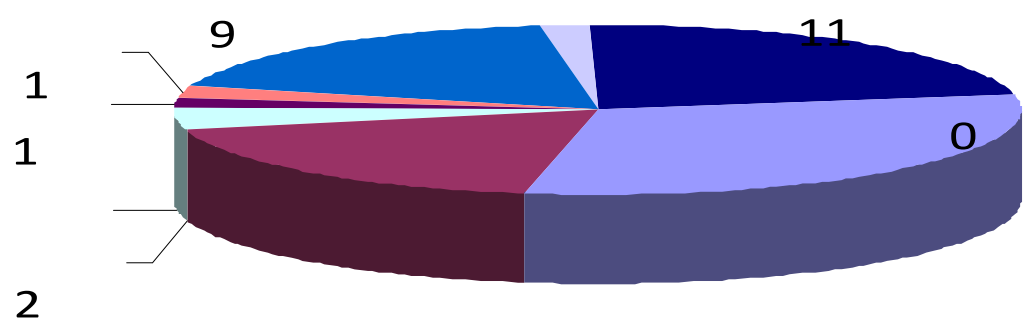

0

9

15

$\begin{array}{lll}\text { Poluição da água } & \text { Poluição do ar } & \text { Poluição } \\ \text { Uso abusivo dos } & \begin{array}{l}\text { Perda } \\ \text { Esgoto não tratado da } \\ \text { Outro }\end{array} & \begin{array}{l}\text { Poluicão sonora } \\ \text { Desmatame }\end{array}\end{array}$

FIGURA 4.4 Questão 4.

Na quinta questão, procurou-se saber a visão dos alunos daqui a quarenta anos de como seria o Planeta Terra. 63\% (10) mais preservado e com pessoas que não destruam ele, 31\%(5) com menos queimadas nas florestas, 6\%(1) destruído e sem floresta. A maioria dos alunos acredita que nosso Planeta vai estar mais preservado, pois as pessoas que hoje tem aula de educação ambiental (conscientização/ sustentabilidade) estarão mais conscientes de suas ações. 
HACK \& WEBER, vol.(4), n4, p. 801-815, 2011. Monografias Ambientais (e-ISSN: 2236-1308)

REMOA

5 - Como você espera ver o Planeta Terra, daqui a 40 anos?

$6 \% \quad 0 \%$

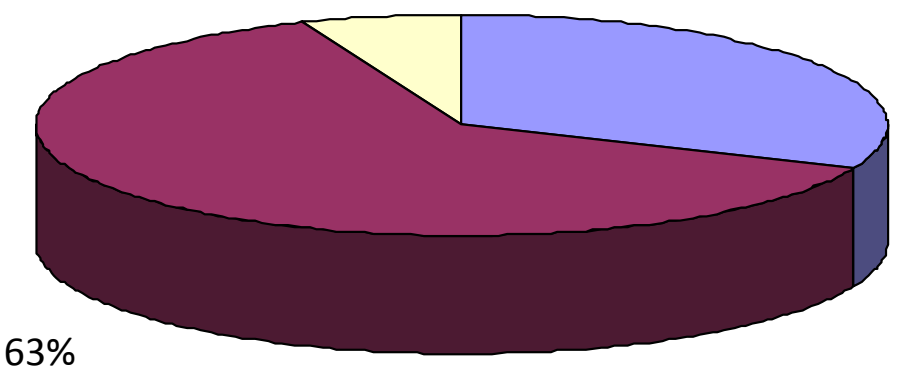

a Cam menos queimadas nas florestas

b Mais preservado e com pessoas que não destruam ele c Destruído e sem florestas

d Nenhuma das respostas

Figura 4.5 Questão 5

\section{CONSIDERAÇÕES FINAIS}

Entretanto, o elemento mais indicado para reverter essa situação caótica do planeta, é justamente o responsável pelo caos, ou seja: O Homem!

O ser humano está mais preocupado com o seu conforto, com o seu modo de vida Os problemas ambientais ficam relegados a um segundo plano ou nem são reconhecidos.

O presente trabalho é parte de um esforço para compreender a resistência que alguns indivíduos apresentam em se relacionar com o meio em que vivem excluindo-se do mesmo. Persiste ainda a idéia de que a natureza está aí para "servir ao homem simplesmente".

Depois de efetivada a pesquisa e de acordo com os resultados obtidos, foi possível estabelecer e destacar a seguintes considerações.

Os alunos participantes do projeto tem conhecimento das questões ambientais, que foram evidenciadas durante a realização da oficina de reciclagem. Os alunos aprenderam um pouco mais sobre como reciclar papel; e todo o processo que esse passa para se transformar em outros objetos, como cartão, ponteira de lápis, caixas, flores e outros objetos possíveis de serem realizadas com o papel reciclado que antes era jogado fora.

Dessa forma a criança ou adolescente que está envolvida em um projeto ambiental consegue verificar os resultados obtidos pela sua ação transformadora, e futuramente se tornará um 
HACK \& WEBER, vol.(4), n4, p. 801-815, 2011. Monografias Ambientais

REMOA

cidadão crítico e consciente do seu trabalho na comunidade, buscando alternativas visando sanar eventuais problemas ambientais.

A Educação Ambiental tem condições de proporcionar questionamentos e debates que mostrem a importância de se pensar no mundo, de oferecer a possibilidade do ser huma viver em harmonia e dar continuidade à sua história, assumindo o compromisso de garanti sua própria sobrevivência e a de seus descendentes.

\section{BIBLIOGRÁFIAS CONSULTADAS}

ALMEIDA, J. A. Pesquisa em extensão rural: um manual de metodologia. Brasília: MEC/ABEAS, 1989.

BARROS, Carlos; PAULINO, Wilson Roberto - Ciências, O meio Ambiente; $5^{\circ}$ série, São Paulo, ed. Àtica, 2003.

Carlos; PAULINO, Wilson Roberto - Ciências, Os Seres Vivos. São Paulo, ed.Ática, 2002.

BALERINI, Samuel. O meio ambiente em debate. São Paulo: ed. Moderna, 2000.

FREIRE, Paulo. Pedagogia da Autonomia: Saberes necessários à prática educativa-7ํed., Rio de Janeiro: Paz e Terra. 1998.

FREIRE, Paulo. Política e educação. São Paulo; Cortez, 1998.

GRESSLER, L. A. Introdução à pesquisa: Projetos e relatórios. 2. ed. São Paulo: Loyola, 2004.

MELLER, Cleria Bitencorte. Compensação Florestal: eixo articulador de ações em educação ambiental. ljuí: ed. UNIJUÍ, 2002.

MINAYO, M. C. S. et al. Pesquisa Social: teoria, método e criatividade. Petrópolis: Vozes, 1994.

MOTA, Paulo Roberto 0 meio Ambiente, São Paulo, ed. Àtica, 2003. PARASURAMAN, A. Marketing Research. Toronto: Addison Wesley Publishing Company, 1986.

TRIVIÑOS, A. N. S. Introdução à pesquisa em ciências sociais: a pesquisa qualitativa em educação. São Paulo: Atlas, 1987.

ZAMBERLAM, Jurandir; FRONCHETI, Alceu - Agricultura Ecológica; preservação do pequeno agricultor e do meio ambiente. Petrópolis, ed. Vozes, 2001.

UNIVERSIDADE FEDERAL DE SANTA MARIA. PRPGP. Estrutura e apresentação de monografias, dissertações e teses - MDT/UFSM. 6. ed. Santa Maria: Ed. da UFSM, PRPGP, 2006. 